\title{
A Novel Tool to Predict the Cosmetic Outcome after Circumcision: Penile Visibility Index
}

\author{
Ilker Akyol*, Hasan Soydan, Hasan Kocoglu, Ferhat Ates, Kenan Karademir, Kadir Baykal \\ GATA Haydarpasa Teaching Hospital, Department of Urology, Istanbul, Turkey \\ Email: "ilkerakyol@yahoo.com
}

Received 20 March 2014; revised 19 April 2014; accepted 15 May 2014

Copyright (C) 2014 by authors and Scientific Research Publishing Inc.

This work is licensed under the Creative Commons Attribution International License (CC BY).

http://creativecommons.org/licenses/by/4.0/

c) (i) Open Access

\begin{abstract}
Objectives: We aimed to evaluate the circumcision status and complications, and the value of penile visibility index in predicting circumcision complications among elementary school children. Patients and Methods: Elementary school students were evaluated with physical exam in terms of circumcision complications. Visible penile length/stretched penile length ratio was calculated for each subject and recorded as penile visibility index (PVI). Data were assessed with SPSS 15.0 software. Results: Average age was $9.04(5$ - 14) years. Circumcision complications were detected in 84 of 361 circumcised subjects $(23.2 \%)$. There was no relationship between age at circumcision and complications $(p>0.05)$. Concealed penis was detected in $3.6 \%$ of all subjects. Mean PVI was significantly different between cases with and without glanular adhesion, and between cases with and without residual prepuce. On the overall, mean PVI in complication and no complication groups were 0.52 and 0.59 respectively, and the difference was statistically significant $(p<0.001)$. Conclusion: PVI calculation before circumcision, might help predict the cosmetic outcome of circumcision beforehand.
\end{abstract}

\section{Keywords}

Circumcision, Concealed Penis

\section{Introduction}

Circumcision has been one of the most frequently performed surgeries since ancient times. It is estimated that one third of the males in the world are circumcised [1]. Circumcision is performed due to cultural and religious

"Corresponding author.

How to cite this paper: Akyol, I., Soydan, H., Kocoglu, H., Ates, F., Karademir, K. and Baykal, K. (2014) A Novel Tool to Predict the Cosmetic Outcome after Circumcision: Penile Visibility Index. International Journal of Clinical Medicine, 5, 605-610. http://dx.doi.org/10.4236/ijcm.2014.510082 
reasons among Muslims and Jews [2]. Circumcision rate is very low in European countries [3] [4] whereas it is quite common in the USA $(80 \%-85 \%)$ for medical reasons [5] [6]. The majority of the population in Turkey is Muslim, and circumcision rate is $99 \%$ [7]. How, when and who performs circumcision depends on cultural factors and why it is performed. Neonatal circumcision is performed by doctors and nurses at the hospitals, but religious circumcision is frequently done by traditional circumcisers on sites out of hospitals [2] [4] [6]-[10].

The indications and benefits of circumcision have been well-defined [5]. Structural anomalies of penis and uncorrected coagulopathies are contraindications to circumcision. Concealed penis, a frequently ignored anomaly of the penis, is missed during a routine circumcision at times, and complications requiring secondary interventions may occur [11]-[13].

We evaluated the circumcision properties and complications among a group of elementary school students aged 6 - 12 years, and assessed the utility of penile visibility index (PVI) in predicting the complications in a retrospective analysis.

\section{Methods}

Males at elementary schools from three different socioeconomic regions of Istanbul were included in the study after parental informed consents were obtained. Age at circumcision $(\mathrm{AaC})$ and operator who performed the circumcision as the parents recalled were recorded. Age groups were categorized as $<2,2-6$ and $>6$ years. Complications related with circumcision were assessed with physical exam. Penile length (PL) from glans edge to radix penis was measured by one Urologist both when penis was relaxed and stretched. A stretched PL below 2.5SD of average PL according to age was referred to as micropenis, while a penis with a normal stretched length but which was not noticeable on the body surface from the lateral view was defined as concealed penis. The ratio of visible PL to stretched PL was calculated for each subject and recorded as PVI, which was used to describe the intermediate group of penises between wholly visible ones and concealed ones (Figure 1). In this manner, the smaller the PVI got, the more concealed a penis it described, while a more visible penis had a PVI close to 1. A possible relationship between PVI and some circumcision complications (secondary phimosis, glanular adhesion, insufficient circumcision, bad cosmesis) was investigated. Bad cosmesis referred to uneven incision lines and bad mucosal healing. Data were analyzed using SPSS ${ }^{\circledR}$ for Windows 15.0 software. MannWhitney $\mathrm{U}$ test was used to investigate the relationship of circumcision complications between PVI, and between AaC.
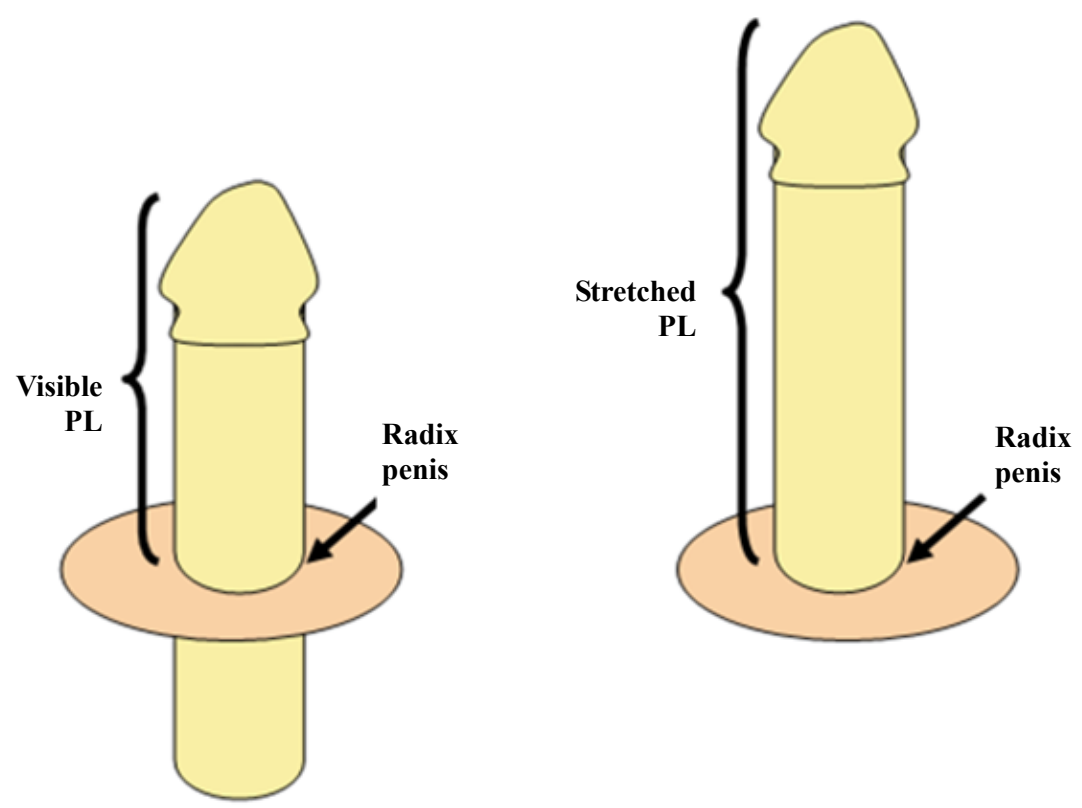

Penile visibility index: Ratio of visible PL to stretched PL*

PL: Penile Length

Figure 1. Calculation of penile visibility index. 


\section{Results}

Informed consents from the parents of 415 students could be obtained out of $1200(34.6 \%)$ who were invited to participate in the study. Average age was 9.04 (5 - 14) years. 361 of 415 children examined (86.9\%) were circumcised. The distribution of 361 subjects who were circumcised according to AaC were as follows: $<2$ years: $27.9 \%$; 2 - 6 years: $45.9 \%$; $>6$ years: $26.2 \%$. The professions doing circumcision and corresponding number of subjects were Urologist: 36 (9.97\%), Pediatric Surgeon: 73 (20.22\%), General Surgeon: 43 (11.9\%), General Practitioner: 25 (6.92\%), Surgical Technician: 23 (6.37\%), other and unknown: 161 (44.59\%).

Circumcision-related complications were detected in 84 subjects $(23.2 \%)$ such that bad cosmesis in 24 , glanular adhesion in 8 , residual prepuce in 52 subjects. No secondary phimosis and glans amputation were found. There was no significant relationship between $\mathrm{AaC}$ and complication rate $(\mathrm{p}>0.05)$ (Table 1 ). Concealed penis (CP) was detected in 15 subjects (3.6\%) among all including uncircumcised ones. We were unable to identify whether concealment was due to primary or secondary to circumcision.

Circumcised subjects were grouped according to whether glanular adhesion, residual prepuce, or bad cosmesis were present or not, and mean PVI was also calculated for each group. Mean PVI was significantly different between cases with and without glanular adhesion, and between cases with and without residual prepuce. On the contrary, mean PVI of the cases with and without bad cosmesis were statistically similar (Table 2). On the overall, mean PVI in complication and no complication groups were 0.52 and 0.59 respectively, and the difference was statistically significant $(\mathrm{p}<0.001)$.

\section{Discussion}

Circumcision rate approaches to $100 \%$ in Turkey [7] and it is greatly affected by some social parameters such as income, education, and living place. Circumcision under age 1 year and traditional circumciser rates are $14.8 \%$ and $13.3 \%$ in Ankara [8] and 58.4\% and 74.5\% in Gaziantep [9], respectively, which are two distant cities in Turkey. The more educated the parents are, the greater the rates of hospital circumcision and older age circumcision [8] [9]. In the current study, circumcision at 2 to 6 years rate was $45.9 \%$. The complication rate is greater after circumcisions performed by traditional circumcisers [14]. Studies from our country conclude that severe and unexpected complications occur after circumcisions performed by traditional circumcisers [7] [15]-[19]. A study from Iran [2] has corroborated this, while an African study reported similar complication rates between traditional circumcisers and doctors [20], though only the $35 \%$ of circumcisions were performed by doctors in the latter. In another article, majority of the 56 children applying for circumcision revision were circumcised by Pediatricians or Pediatric residents [12]. Although most of the complications we detected were minor ones, it is

Table 1. Complication rates according to age groups.

\begin{tabular}{cccc}
\hline Age groups (years) & Bad cosmesis (n) & Glanular adhesion (n) & Residual prepuce (n) \\
\hline$<2$ & 3 & 1 & 15 \\
$2-6$ & 12 & 3 & 18 \\
$>6$ & 9 & 4 & 19
\end{tabular}

$\mathrm{p}>0.05$.

Table 2. Comparison of PVI values between cases with and without complications.

\begin{tabular}{|c|c|c|c|c|c|c|}
\hline & \multicolumn{2}{|c|}{ Glanular adhesion } & \multicolumn{2}{|c|}{ Residual prepuce } & \multicolumn{2}{|c|}{ Bad cosmesis } \\
\hline & Present & Absent & Present & Absent & Present & Absent \\
\hline $\mathrm{n}$ & 8 & 353 & 54 & 307 & 18 & 343 \\
\hline Minimum PVI & 0.25 & 0.29 & 0.27 & 0.17 & 0.33 & 0.17 \\
\hline Maximum PVI & 0.67 & 0.82 & 0.82 & 0.89 & 0.68 & 0.89 \\
\hline Mean PVI & 0.49 & 0.59 & 0.52 & 0.59 & 0.57 & 0.59 \\
\hline$P$ value & \multicolumn{2}{|c|}{0.026} & \multicolumn{2}{|c|}{0.001} & \multicolumn{2}{|c|}{0.324} \\
\hline
\end{tabular}


apparent that we report a high incidence of complications. This might be because a large number of parents did not know the profession of the operator doing the circumcision, or a considerable percentage of circumcisions were performed by people who were not even doctors in our study cohort. This indicates that circumcision is considered as a traditional act rather than being a surgical procedure, and medical aspect of the outcome is underestimated.

Most frequent circumcision complications reported in Turkey are glanular adhesions and insufficient circumcision (residual prepuce) [7] [15] [19]. Other complications are subcutaneous granuloma, meatal stenosis, penile rotation, trapped penis, secondary phimosis, urethral fistula, acquired hypospadias, excessive resection of penile skin, and glans amputation [2] [12] [14] [20]. Complication rate in our cohort was $23.2 \%$ and most of them were insufficient circumcisions. CP was found in 15 (3.6\%) of the subjects. The term "concealed" was preferred, which does not imply any etiologic factor, since we did not differentiate between the pathological mechanisms causing the clinical picture (entrapment, or congenital).

$\mathrm{CP}$ refers to an anomaly such that penis appears to be short though its length is normal. CP may be divided into 3 groups according to the Maizels classification which is based on the etiologic mechanism: Buried penis, webbed penis, trapped penis [21]. One or more mechanisms may contribute to concealment in each case. Buried penis describes a condition that a penis remains under the level of pubic skin due to the excessive suprapubic fat, or due to the loose attachment of penile skin to the Dartos. In webbed penis, there is extra skin between scrotal raphe and distal penis obscuring the penoscrotal angle. Trapped penis refers to a condition that a normal penis is depressed under the skin following a surgical procedure, generally a circumcision, and looks concealed. Williams et al reported a rate of $9 \% \mathrm{CP}$ among those applying for routine circumcision, and they performed a penoplasty rather than a circumcision in these cases [11]. Same study reported a $63 \% \mathrm{CP}$ among those applying for a circumcision revision (26\% trapped penis, and $37 \%$ insufficient circumcision). It is possible that one may refrain from excising sufficient prepuce in order to avoid a more complicated picture in a case with partial $\mathrm{CP}$, and insufficient circumcision may take place. In a baby with $\mathrm{CP}$, a generous excision of penile skin in an effort to make the penis visible, leads to a crippled problem of trapped penis with almost no local penile skin surrounding the penis that will require flaps or grafts for correction. Borsellino et al. reported that a staged revision surgery was required in majority of their cases since penile shaft skin was also excised along with the prepuce [22].

Complete $\mathrm{CP}$ is a contraindication to circumcision. However, there are intermediate forms with differing degrees of concealment, and the outcome of circumcision in cases with partial CP remains to be described. If a relationship between the degree of concealment and circumcision complications could be established, surgical technique for circumcision could be adjusted, and parents could be informed accordingly prior to the circumcision. By recognizing the intermediate forms preoperatively, dissatisfaction due to bad cosmetic outcome might be prevented. For this reason, in an effort to obtain a measurable parameter defining the degree of concealment, we used an index, i.e., the ratio of the visible penile length over the body surface to the stretched penile length (Figure 1), and investigated its relationship with postoperative complications. Our analysis revealed a significant difference between mean PVI values of cases with and without circumcision complications in our cohort. Mean PVI was significantly different between cases with and without glanular adhesion, and between cases with and without residual prepuce (Table 2). This translates into clinical practice such that the smaller the PVI is, the higher the likelihood of cosmetic problems after a routine circumcision is. A practical application of PVI may be achieved with a "rehearsal" of the circumcision. This is performed by recognizing the limits of the penile skin and mucosa, and the future incision lines when both penis is stretched and relaxed. This maneuver serves to estimate the extent of folding of the skin-mucosa anastomosis. If the prospective suture line projects distally to where the glans becomes narrower, this implies that glanular adhesions, secondary phimosis or penile entrapment are likely, in case a fibrotic healing process takes place after circumcision. It was revealed in various trapped penis series that approximately half of the cases had undergone an unsuccessful penile surgery, mostly circumcision [23] [24]. According to our findings, this is most likely when PVI equals to or is lower than roughly 0.5 . For this reason, a penis should be assessed before circumcision in terms of "how visible" or "how concealed" it is. Especially the professionals doing routine circumcision should be informed about the entity of $\mathrm{CP}$, and cautioned that they refer the suspicious cases to where patients can receive appropriate treatment.

We were unaware of the precircumcision appearance of the penises, and circumcision itself might have contributed to the concealment in some subjects, or the PVI may have changed after the circumcision, and this decreases the power of our analysis. However, ours is a descriptive pilot study, results of which indicate that prospective studies investigating the ability of PVI in predicting the outcome of circumcision are worthwhile. 
Circumcision is a frequently performed surgery around the world. Some circumcision complications appear to be more frequent among cases with complete or partial CP. Especially the partial CP often remains unrecognized before circumcision, and this leads to increased rates of cosmetic complications, such as glanular adhesions or secondary phimosis. Estimating the preoperative PVI may help predict the cosmetic outcome after circumcision, which in turn might alter the management. For example, if a circumcision is being performed for non-health-related reasons, the procedure could be delayed until the penis grows out of partial concealment. If the circumcision seems inevitable in a case with partially concealed penis, a more careful followup by the parents and surgeon could be planned, such that, penile skin is frequently slid back by the parents after circumcision to prevent adhesions, and the patient is called to the office more frequently to make sure that parents did their part effectively.

\section{Conclusion}

Penile visibility index calculation before circumcision, might help predict some cosmetic complications beforehand, and provide better information for the parents. Prospective studies are needed to corroborate our analysis.

\section{Acknowledgments}

None of the authors has any direct or indirect commercial financial incentive associated with publishing the article. There is no source of extra-institutional funding, particularly that provided by commercial sources.

\section{Financial Disclosure}

None declared.

\section{Funding/Support}

None declared.

\section{References}

[1] Gatrad, A.R., Sheikh, A. and Jacks, H. (2002) Religious Circumcision and the Human Rights Act. Archives of Disease in Childhood, 86, 76-78. http://dx.doi.org/10.1136/adc.86.2.76

[2] Yegane, R., Kheirollahi, A., Salehi, N., et al. (2006) Late Complications of Circumcision in Iran. Pediatric Surgery International, 22, 442-445. http://dx.doi.org/10.1007/s00383-006-1672-1

[3] Klavs, I. and Hamers, F.F. (2008) Male Circumcision in Slovenia: Results from a National Probability Sample Survey. Sexually Transmitted Infections, 84, 49-50. http://dx.doi.org/10.1136/sti.2007.027524

[4] Cathcart, P., Nuttall, M., van der Meulen, J., et al. (2006) Trends in Paediatric Circumcision and Its Complications in England between 1997 and 2003. British Journal of Surgery, 93, 885-890. http://dx.doi.org/10.1002/bjs.5369

[5] Edgar, J. and Schoen, M.D. (2006) Ignoring Evidence of Circumcision Benefits. Pediatrics, 118, 385-387. http://dx.doi.org/10.1542/peds.2005-2881

[6] Drain, P.K., Halperin, D.T., Hughes, J.P., Klausner, J.D. and Bailey, R.C. (2006) Male Circumcision, Religion, and Infectious Diseases: An Ecologic Analysis of 118 Developing Countries. BMC Infectious Diseases, 6, 172. http://dx.doi.org/10.1186/1471-2334-6-172

[7] Atikeler, M.K., Gecit, I., Yuzgec,V. and Yalcın, O. (2005) Complications of Circumcision Performed within and outside the Hospital. International Urology and Nephrology, 37, 97-99. http://dx.doi.org/10.1007/s11255-004-6077-2

[8] Sahin, F., Beyazova, U. and Akturk, A. (2003) Attitudes and Practices Regarding Circumcision in Turkey. Child: Care, Health and Development, 29, 275-280. http://dx.doi.org/10.1046/j.1365-2214.2003.00342.x

[9] Sivasli, E., Bozkurt, A.I., Ceylan, H. and Coskun, Y. (2003) Gaziantep bölgesindeki sünnet ileilgili bilgi, tutum ve davranışları. Cocuk Sagligi ve Hastaliklari Dergisi, 46, 114-118.

[10] Muula, A., Prozesky, H.W., Mataya, R.H. and Ikechebelu, J.I. 2007) Prevalence of Complications of Male Circumcision in Anglophone Africa: A Systematic Review. BMC Urology, 7, 4. http://dx.doi.org/10.1186/1471-2490-7-4

[11] Williams, C.P., Richardson, B.G. and Bukowski, T.P. (2000) Importance of Identifying the Inconspicuous Penis: Prevention of Circumcision Complications. Urology, 56, 140-143. http://dx.doi.org/10.1016/S0090-4295(00)00601-4

[12] Brisson, P.A., Patel, H.I. and Feins, N.R. (2002) Revision of Circumcision in Children: Report of 56 Cases. Journal of 
Pediatric Surgery, 37, 1343-1346. http://dx.doi.org/10.1053/jpsu.2002.35005

[13] Sivakumar, B., Brown, A.A. and Kangesu, L. (2004) Circumcision in "Buried Penis"-A Cautionary Tale. Annals of the Royal College of Surgeons of England, 86, 35-37. http://dx.doi.org/10.1308/003588404772614669

[14] Ahmed, A., Mbibu, N.H., Dawam, D. and Kalayi, G.D. (1999) Complications of Traditional Male Circumcision. Annals of Tropical Paediatrics, 19, 113-117. http://dx.doi.org/10.1080/02724939992743

[15] Ceylan, K., Koseoglu, B., Yilmaz, Y., et al. (2007) Severe Complications of Circumcision: An Analysis of 48 Cases. Journal of Pediatric Urology, 3, 32-33. http://dx.doi.org/10.1016/j.jpurol.2006.02.009

[16] Ozdemir, E. (1997) Significantly Increased Complication Risks with Mass Circumcisions. British Journal of Urology, 80, 136-139. http://dx.doi.org/10.1046/j.1464-410X.1997.00218.x

[17] Demirseren, M.E. and Gokrem, S. (2004) Circumcision in Unqualified Hands: A Significant Risk of Complication. Plastic and Reconstructive Surgery, 113, 1090-1092. http://dx.doi.org/10.1097/01.PRS.0000107735.19836.60

[18] Akoz, T., Erdogan, B., Gorgu, M., Aslan, G. and Altintas, H. (1998) Unusual Complications of Circumcision. Plastic and Reconstructive Surgery, 101, 1915-1918. http://dx.doi.org/10.1097/00006534-199806000-00021

[19] Williams, N. and Kapila, L. (1993) Complications of Circumcision. British Journal of Urology, 80, 1231-1236.

[20] Okeke, L.I., Asinobi, A.A. and Ikuerowo, O.S. (2006) Epidemiology of Complications of Male Circumcision in Ibadan, Nigeria. BMC Urology, 6, 21. http://dx.doi.org/10.1186/1471-2490-6-21

[21] Maizels, M., Zaontz, M. and Donovan, J. (1986) Surgical Correction of the Buried Penis: Description of a Classification System and a Technique to Correct the Disorder. The Journal of Urology, 136, 268-271.

[22] Borsellino, A., Spagnoli, A., Vallasciani, S., Martini, L. and Ferro, F. (2007) Surgical Approach to Concealed Penis: Technical Refinements and Outcome. Urology, 69, 1195-1198. http://dx.doi.org/10.1016/j.urology.2007.01.065

[23] Bergeson, P., Hopkin, R.J., Bailey Jr., R.B., McGill, L.C. and Piatt, J.P. (1993) The Inconspicuous Penis. Pediatrics, 92, 794-799.

[24] Casale, A.J., Beck, S.D. and Cain, M.P. (1999) Concealed Penis in Childhood: A Spectrum of Etiology and Treatment. The Journal of Urology, 162, 1165-1168.

\section{Abbreviations \\ PVI: penile visibility index \\ AaC: Age at circumcision \\ PL: Penile Length \\ CP: Concealed Penis}

